\title{
University Professor Emeritus Dr. Georg Riccabona
}

\section{Irene Virgolini ${ }^{1}$}

Published online: 17 May 2019

(C) Springer-Verlag GmbH Germany, part of Springer Nature 2019

Professor Riccabona was born on June 12, 1933 in Innsbruck. He studied Medicine in Innsbruck as well as in Paris and received his Medical Degree in January 1958. He then began his internship in Surgery and Internal Medicine, worked for a short time as an assistant of Pathology and Anaesthesiology and finally completed his training in Surgery under Professor Paul Huber.

In 1961, Professor Riccabona established the first Nuclear Medicine procedures in thyroid diseases in the so-called "Isotope Laboratory" located at the Surgery Department of Innsbruck, after he had completed a basic Nuclear Medicine education in Hamburg-Eppendorf under Professor Wolfgang Horst in 1960 .

In 1962 and 1963 Professor Riccabona worked with a scholarship at the Massachusetts General Hospital in Boston, USA, where under Professor John B. Stanbury he got particularly familiar with thyroid diagnoses using radioactive isotopes.

After returning to the Hospital at Innsbruck, Professor Riccabona finished his specialist registrar in Surgery in 1965, but his heart already belonged to Nuclear Medicine.

In 1964, the first outpatient service for the diagnosis and treatment of thyroid diseases was set up at the Hospital in Innsbruck, and the first gamma camera was purchased in Austria. The range of Nuclear Medicine examinations was then extended to liver, kidney, brain, spleen, lung, as well as skeletal diagnosis, and the in vitro tests were further established.

In 1968, Professor Riccabona received his post-doctoral lecturing qualification with the title "The Endemic Struma in Tyrol", in the subject "Surgery with Special Consideration of the Isotope Application". In the same year, the Isotope Outpatient Service moved to the basement of the Surgery

Irene Virgolini

Irene.Virgolini@i-med.ac.at

1 Department of Nuclear Medicine, Medical University of Innsbruck, Anichstraße 35, 6020 Innsbruck, Austria building, where it is still located today. To this day, not only the Thyroid Outpatient Clinic, but also the Conventional Nuclear Medicine Clinic and the PET-Centre with two PET/ CTs have been installed.

Furthermore, in 1969, the first Nuclear Medicine Therapy Ward in Austria for high-dose radionuclide therapies was put into operation, located on the first floor of the Surgical building, which was expanded and renewed in 2003 with 13 treatment beds.

In 1976, Professor Riccabona became Ordinary Professor of the first Austrian Nuclear Medicine University Department.

Professor Riccabona has essentially contributed to the great development of Nuclear Medicine in recent years. At the Medical University Innsbruck, Department of Nuclear Medicine, research was always of utmost importance and several researchers worked under Professor Riccabona, including Günther Galvan (former Director of the Landeskrankenhaus Salzburg), Peter Lind (Director of the Klinikum Klagenfurt), Werner Langsteger (Director of the Krankenhaus der Barmherzigen Brüder, Linz), Roy Moncayo (Deputy Director of the Department of Nuclear Medicine in Innsbruck), and Clemens Decristoforo (Department of Nuclear Medicine in Innsbruck), all of them long-serving and active members of EANM.

In 1996, I met Professor Riccabona because of my MAURITIUS Study (Multicenter Analysis of a Universal Multicenter Initiative: a European Study). At that time, Professor Riccabona brought MAURITIUS from Vienna to Innsbruck. Thus, the well-established somatostatin receptor therapy of today was brought in its very early phase to Innsbruck. When, after Professor Riccabona's retirement, I became Director of the Medical University Innsbruck in 2003, I could thus start to work with a well-trained team for which I am very grateful to Professor Riccabona.

Professsor Georg Riccabona was one of the cofounders of the Austrian Society for Nuclear Medicine in 1968, and was the president from 1968 to 1969.

In 1985, Professor Riccabona played a significant role in the foundation of the European Association of Nuclear 
Medicine, the EANM, and was the President of the EANM from January 1986 to December 1988. Soon after his retirement in 2000, Professor Riccabona became an Honorary Member of the EANM in 2003.

I would like to mention an anecdote on the occasion of the 80th birthday of Professor Riccabona: Emeritus Professer Rudolf Höfer from Vienna University, at over 90 years of age, was invited for the Annual Tyrolean Nuclear Medicine Congress in Innsbruck and travelled alone by train. In his speech, Professor Höfer mentioned both the East (Vienna) and the West (Innsbruck) of Nuclear Medicine in Austria in a positive light, pointing to the controversial discussions and differences - not to say the long-lasting competitionbetween both institutions and presenting to Professor Riccabona a self-made birthday cake, as a small gesture of final peace (Figs. 1 and 2).

Not only for his scientific engagement but also following participation in numerous IAEA projects, Professor Riccabona became well known around the world, especially in the field of thyroid diseases. In 2015, for his life-long pioneering work, Professor Riccabona received the Lifetime Achievement Award from the World Association of Radionuclide Therapy (WARMTH), which also included the honorary membership of WARMTH.

Professor Riccabona has always been very ambitious to raise funds for the clinic and science. He was one of the first Nuclear Medicine physicians who, in 1995-1996, paid for his work on "Endemic Struma" with an NIH grant.

I am proud to direct the Department of Nuclear Medicine at the Medical University of Innsbruck, which I have done for the last 15 years since the retirement of Professor Georg Riccabona, and where we have one of the largest teams in Europe that continues to focus on Nuclear Medicine therapy,

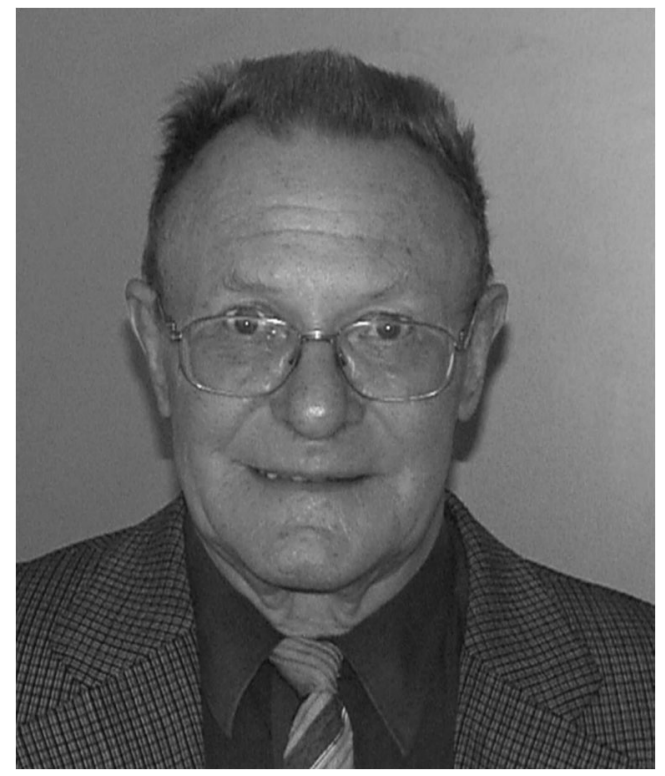

Fig. 1 Portrait Univ.-Prof. Dr. emer. Georg Riccabona

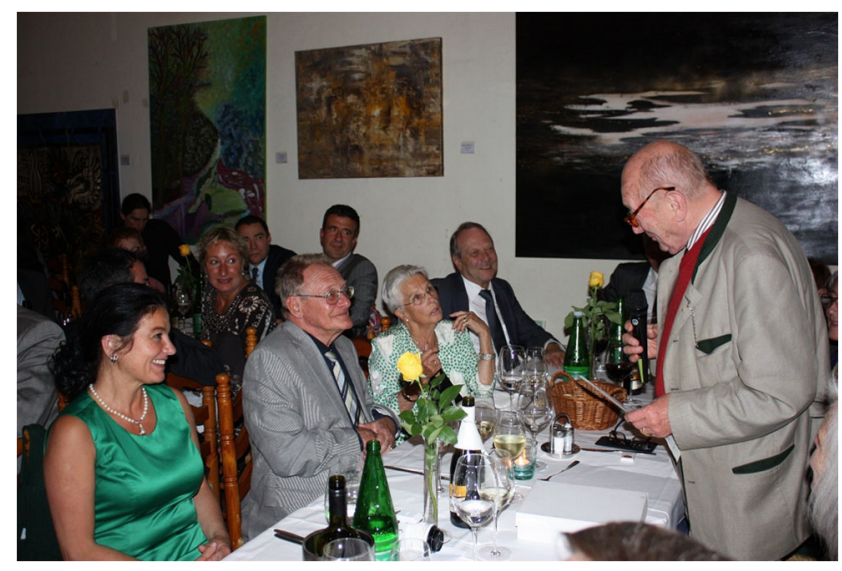

Fig. 2 Univ.-Prof. Dr. emer. Höfer, University of Vienna presenting a self-made birthday cake at Univ.-Prof. Dr. emer. Riccabona's 80th birthday (from right to left, in the front: Univ.-Prof. Dr. emer. Rudolf Höfer, Univ.-Prof. Dr. emer. August Schubiger [ETH Zürich], Felicitas Riccabona, Univ.-Prof. Dr. emer. Georg Riccabona, Univ.-Prof. Dr. Irene Virgolini [Medical University Innsbruck], in the back: Univ.-Prof. Dr. Thomas Beyer [Medical University Vienna], Univ.-Prof. Dr. Marcus Hacker [Medical University Vienna])

which is now experiencing its renaissance. Targeted therapy has its historical origin in thyroid carcinoma therapy with radioiodine, iodine 131, the first model of precision medicine that Professor Riccabona introduced so successfully in Austria.

Professor Riccabona passed away on January 13, 2019. He left behind his wife, Dorothea Felicitas Riccabona, to whom he was married since 1956, and also five children, 15 grandchildren and several great-grandchildren.

Professor Riccabona's hobbies were painting, hiking and gardening.

With him the EANM loses not only one of its cofounders, but also an outstanding pioneer of Nuclear Medicine.

\section{Compliance with ethical standards}

Conflict of interest The author declares that she has no conflict of interest related to this paper.

This article does not contain any studies with humans or animals.

Publisher's note Springer Nature remains neutral with regard to jurisdictional claims in published maps and institutional affiliations. 